INTERSECTIONAL ARITHMETIC: HOW GENDER, RACE AND MOTHER TONGUE

COMBINE TO IMPACT IMMIGRANTS' WORK OUTCOMES

\author{
Stacey R Fitzsimmons* \\ Associate Professor of International Business \\ Peter B. Gustavson School of Business \\ University of Victoria, CANADA \\ Jen Baggs \\ Associate Professor of International Business \\ Peter B. Gustavson School of Business \\ University of Victoria, CANADA \\ Mary Yoko Brannen \\ Honorary Professor of International Business \\ Copenhagen Business School \\ * Corresponding author. Phone: +1 250-472-4787 email: sfitzsim@uvic.ca
}

Fitzsimmons, S. R., Baggs, J., \& Brannen, M. Y. (2020). Intersectional arithmetic: How gender, race and mother tongue combine to impact immigrants' work outcomes. Journal of World Business, 55(1). doi.org/10.1016/j.jwb.2019.101013

Acknowledgements: This research was supported by funds to the Canadian Research Data Centre Network (CRDCN) from the Social Sciences and Humanities Research Council (SSHRC), the Canadian Institute for Health Research (CIHR), the Canadian Foundation for Innovation (CFI), and Statistics Canada. It was also directly supported by a SSHRC grant. Although the research and analysis are based on data from Statistics Canada, the opinions expressed do not represent the views of Statistics Canada. 


\title{
INTERSECTIONAL ARITHMETIC: HOW GENDER, RACE AND MOTHER TONGUE COMBINE TO IMPACT IMMIGRANTS' WORK OUTCOMES
}

\author{
ABSTRACT. We use an intercategorical approach to intersectionality to quantify pay and \\ attainment of supervisory positions for groups of immigrants and their descendants who also \\ vary in gender, mother tongue, and race. Using a Canadian nationally representative sample of \\ 20,000 employees across 6000 firms, we find a $\$ 10,000$ spread in annual pay between the groups \\ with the most advantages and those experiencing the most barriers, loosely corresponding to an \\ additive model of intersectional benefits and barriers. The effects of immigrant generation are \\ partially mitigated by the degree to which firms are internationally-oriented, indicating that \\ international businesses may help to reduce inequities.
}

Keywords: immigrants, labor market, intersectional, gender, language, race. 


\section{INTERSECTIONAL ARITHMETIC: HOW GENDER, RACE AND MOTHER TONGUE COMBINE TO IMPACT IMMIGRANTS' WORK OUTCOMES}

Popular lore about employment success within immigrant-receiving countries says that the first generation suffers for the sake of their children, who flourish. This immigrant story explains poor workplace outcomes for first-generation immigrants through systematic and uncontroversial barriers such as inadequate language skills, lack of insider cultural knowledge or limited access to well-placed social networks (Algan, Dustmann, Glitz, \& Manning, 2010; Bratsberg, Ragan Jr., \& Nasir, 2002). Evidence supports this story, with consistent findings across Canada, the U.S, France, Germany and UK that the children of immigrants subsequently receive higher wages and more promotions than their parents (Algan et al., 2010; Morissette \& Sultan, 2013; Pew Research Center, 2013). The vast majority of workforce growth in many developed countries now comes from immigration, such that by $2050,37 \%$ of the U.S. population is predicted to be an immigrant or the child of immigrants, a percentage already surpassed in countries such as Canada, Australia, Singapore and Qatar (Pew Research Center, 2013; United Nations, 2013). Thus, the immigrant story is a tale of hope for individuals with an immigrant background, referring collectively to the first generation and their children or grandchildren, and for their receiving countries.

However, this hopeful story falsely assumes immigrant groups are all treated equally in the workplace. Well-known downward pressures on workplace outcomes based on gender, race or mother tongue can overwhelm generational effects, resulting in persistently poor outcomes for some groups across immigrant generations, even while other groups flourish. Research usually adopts theoretical stories about either resources or barriers to compare workplace outcomes for 
individuals with an immigrant background relative to non-immigrants. We refer to nonimmigrants as people who are not the children or grandchildren of immigrants. On one side, international management scholars often build arguments about the additional resources individuals contribute to their organizations as a result of their immigrant backgrounds. Examples include gaining career capital, complex thinking skills, creativity or boundary-crossing networks (Cerdin, Dine, \& Brewster, 2014; Fitzsimmons, 2013; Guo \& Al Ariss, 2015; Hajro, Zilinskaite, \& Stahl, 2018; Leung, Maddux, Galinsky, \& Chiu, 2008; Zikic, 2015) On the other side, labor economists commonly tell a story about structural labor market barriers such as discrimination that result in worse outcomes for individuals with an immigrant background (Algan et al., 2010; Baker \& Benjamin, 1994; Borjas, 1994; Oreopoulos, 2011; Yao \& van Ours, 2015). While evidence supports both effects in isolation, they are rarely combined because they rely on different theoretical arguments and measurement approaches.

Our goal is to create a more accurate picture of workplace outcomes for immigrants and their descendants by testing the relative strength of both upward and downward pressures on pay and attainment of supervisory positions across groups. Our primary research question is, which groups of immigrants and their descendants receive relative premiums or deficits in the workplace, across all combinations of immigrant status, race, gender and mother tongue? We contextualize this story by asking whether these effects vary between firms focused on international or domestic markets. To what degree do international firms moderate outcome gaps across immigrant status, race, gender and mother tongue? We accomplish this goal by adopting an intercategorical approach to intersectionality, explained ahead. This approach allows us to simultaneously test arguments about resources and barriers by examining the pattern of outcomes across groups of individuals. 


\section{Intersectionality: Development and variations}

Intersectionality was founded in the assumption that human experiences are not shaped by single factors working independently, such as nationality or gender or race, but by their combination, creating something distinct from their constituent parts (Crenshaw, 1991; Hancock, 2007; Mahalingam, Balan, \& Haritatos, 2008; Weaver, Crayne, \& Jones, 2016). Kimberlé Crenshaw (1991) coined the term to argue that a firm had discriminated against black women even though this firm employed both black men - who primarily worked in manual labor jobs and white women - who primarily worked in the office. It was further developed in the 1980s by feminist critical race scholars, who argued that most feminist scholarship was about middle-class white women, ignoring the wider range of experiences at the intersection of gender with class and race (Anthias \& Yuval-Davis, 1983; Dill, 1983).

Since then, scholars have worked to develop criteria that distinguishes intersectional from other approaches to the study of race, gender, class and other categories of difference (McBride, Hebson, \& Holgate, 2015). Hancock (2007) argues that intersectional research must assume that relationships between demographic categories are open and fluid, and that the original categories are transformed into something new after intersecting. This approach is consistent with Crenshaw's original conceptualization, which found that discrimination experienced by black women is not the sum of discrimination experienced by women and that by people who are black. It also has methodological implications, where most intersectional research in this tradition use qualitative methods to explore how the set of characteristics for a single group of people combine into something categorically different from any of the originating characteristics to shape their experiences (Hancock, 2007; Warner, 2008). However, researchers have found this approach restricts their ability to compare experiences across groups (Weaver et al., 2016). 
In comparison to Hancock's open, fluid and mutually constituted conceptualization of intersectionality, McCall (2005) endorses three different approaches to intersectionality that vary in how they combine categories: Anticategorical approaches embrace social fluidity and complexity over stable categories; intracategorical approaches adopt a critical stance to the existence of social categories; and intercategorical approaches provisionally adopt stable social categories to document and test patterns across groups. The intercategorical approach is useful for resolving the problem of incomparability across groups (Felski, 1997; Sayer, 1997). We recognize the value in all of these approaches to intersectionality: The fluid, open and mutually constitutive approach is the only way to understand how a particular group's experiences are shaped by their unique combination of categories, while the stable, intercategorical approach is the only way to examine patterns across groups of people (McBride et al., 2015; Özbilgin, Beauregard, Tatli, \& Bell, 2015).

This project therefore contributes to research about immigrant employees by adopting an intercategorical approach to intersectionality. We use this lens to test whether the assumption of additive combinations of categories ever holds, and reveal which specific combinations of categories correspond more closely to non-linear or mutually constituted assumptions. Any groups whose outcomes defy the intercategorical pattern predicted by additive linear combinations merit deep examination using more fluid and open approaches to discover why (McCall, 2005; Warner, 2008; Weaver et al., 2016).

Our intersectional hypothesis predicts pay and attainment of a supervisory position among individuals residing in Canada who were born in other countries ('first-generation immigrants' OECD, 2003) and recent descendants of immigrants (collectively called employees with immigrant backgrounds) relative to non-immigrants. Even small differences in pay or 
hierarchical position produce real and substantial impacts on peoples' lives and well-being and are therefore the most commonly studied workplace outcomes. We predict consistent relationships with both workplace outcomes in all of our hypotheses, based on the degree to which individuals experience upward and downward pressures on pay and hierarchical position as a result of multiple characteristics.

H1: All else being equal, there will be a positive linear trend between sums of barriers and a) pay, and b) attainment of supervisory positions, where sums of barriers are the additive sum of sources of advantage and disadvantage predicted by immigrant generation, race, mother tongue and gender.

The following sections build direct effect hypotheses related to immigrant generation, race, mother tongue and gender, before returning to this intersectional hypothesis to construct the expected linear pattern across groups. Each effect is well-studied in isolation, so we treat them relatively briefly to establish baseline relationships on which to test our primary hypothesis $(\mathrm{H} 1)$ about whether they can be combined additively. We describe upward pressure on workplace outcomes due to a skills premium for individuals with an immigrant background, followed by the dampening effect of four of the most prevalent economic barriers to labor market access and advancement: being a first-generation immigrant (called the generation effect); being a person of color (race effect ${ }^{1}$ ); working in a non-native language (mother tongue effect), and being a

\footnotetext{
${ }^{1}$ People of color is a positive term that refers to individuals who are not white. It is currently used as a preferable alternative to either "visible minority" or "non-white", both of which define this group in contrast to the majority group (Delgado \& Stefancic, 2017). The binary distinction between people of color and white people can be measured with more global consistency than the range of other racial categories, which vary widely across countries.
} 
woman (gender effect ${ }^{2}$ ). Finally we explore how these intersectional effects are moderated by the degree to which organizations are internationally orientated.

\section{Immigrant backgrounds and skills premium}

Immigrant status has the potential to exert both upward and downward pressures on workplace outcomes such as pay and attainment of supervisory positions. Upward pressures occur when individuals with an immigrant background bring new or valuable skills to their organizations as a result of insider access to more than one culture (Fitzsimmons, Liao, \& Thomas, 2017). This insider access may fall anywhere along the spectrum of individual-level multiculturalism, referring to the degree to which individuals identify with, internalize and have knowledge of more than one culture (see Vora et al., in press for more about this spectrum). Internalizing a culture refers to internalizing a set of organized knowledge structures called a cultural schema, including cultural norms, values and beliefs, that help people interpret and select information associated with a culture (Markus, 1977; Markus \& Kitayama, 1991). These schemas act as filters that help us interpret the world around us, communicate meaning and generally function in society (Lücke, Kostova, \& Roth, 2014).

Although some very recent immigrants may still identify with, internalize and have knowledge of only their heritage cultures, most immigrants start to adopt their new cultures soon after immigrating. For example, a 13-country survey study of adolescent immigrants found that the largest group of participants had positive associations with both ethnic and national identities, used both languages, and had friends from both cultures (Berry, Phinney, Sam, \& Vedder, 2006). An interview-based study of 84 skilled adult migrants in Austria found that $89 \%$ identified with

\footnotetext{
${ }^{2}$ Although all four of our barriers are more accurately described as spectrums, we discuss and measure each as binary constructs. This approach is consistent with how each one was measured, and because categories are necessary to construct the intersectional groups we need to test our primary hypothesis.
} 
both cultures, compared to only $7 \%$ who identified primarily with the heritage culture (Hajro et al., 2018). Once an individual has adopted more than one culture to some degree, they are placed somewhere along the spectrum of multiculturalism and can therefore access multiple cultural schemas to make sense of the world around them (Vora et al., in press). In contrast, most nonimmigrants have access to only one cultural schema that becomes their default across situations.

When individuals have access to more than one cultural schema, they commonly develop culture-general skills that can be useful across a wide range of work situations (Benet-Martínez, 2010; Cheng, Lee, Benet-Martínez, \& Huynh, 2014; Lücke et al., 2014). Examples include solving complex problems, leading multicultural teams, negotiating and brokering across cultures (Barner-Rasmussen, Ehrnrooth, Koveshnikov, \& Mäkelä, 2014; Brannen \& Thomas, 2010; Fitzsimmons, Miska, \& Stahl, 2011; Jang, 2017; Tadmor, Galinsky, \& Maddux, 2012). Two meta-analyses in cross-cultural psychology independently found that individuals who identify with at least two cultures tend to have higher levels of behavioral competence, academic achievement and career success, relative to individuals who identify with one culture (Berry et al., 2006; Nguyen \& Benet-Martínez, 2013). This relationship between having access to more than one culture and higher task performance helps to explain why employees with immigrant backgrounds could receive higher pay and more supervisory responsibilities than nonimmigrants. That is, we expect these additional skills should be valued such that individuals with immigrant backgrounds will generally have higher pay and hierarchical positions than nonimmigrant employees. However, this upward pressure on outcomes must be considered together with the downward pressure of being a first-generation immigrant, discussed next.

\section{Economic barriers to access and advancement}


In the following four sections, we theorize the impact of each of the four labor market barriers we combined in our first hypothesis: immigrant generation, race, mother tongue, and gender. These are the most commonly examined labor market barriers for individuals with an immigrant background (Algan et al., 2010; Baker \& Benjamin, 1994; Borjas, 1994; Dustmann \& Fabbri, 2003; Guiliano, Levine, \& Leonard, 2009; Guo \& Al Ariss, 2015; Mahalingam et al., 2008; Morissette \& Sultan, 2013; Oreopoulos, 2011; Yao \& van Ours, 2015). We expect that each of these factors will suppress pay and the attainment of supervisory positions for immigrants and their descendants who are members of one or more of these disadvantaged groups.

Generation effect. Structural barriers limit career progression for first-generation immigrants, explaining why economic arguments about immigrants focus so much attention on the differences between generations. Consistent results indicate that first-generation immigrants experience more and stronger barriers to entry and advancement than later generations (Algan et al., 2010). Social networks demonstrate how structural barriers are particularly strong for firstgeneration immigrants. It has long been known that immigrant social networks are composed primarily of other home-country immigrants, and that this constrains access to the broader pool of host-country employment options (Wilson \& Portes, 1980). For example, Canadian-born males were found to be 20 percentage points more likely to be employed at large firms than immigrant males, because those born domestically had better placed networks at large firms (Morissette \& Sultan, 2013; Stoyanov, Woodward, \& Stoyanova, 2018). A study of small, lowwage firms in The Netherlands found they were more likely to employ immigrants because recruiting happened primarily through kinship networks (Edwards \& Ram, 2006). First- 
generation immigrants have limited domestic work experience, are less likely to have domestic education credentials, and their social networks often limit access to high-value positions.

Recent descendants of immigrants are not expected to experience any of these barriers related to foreign credentials, experience, or constrained social networks, since descendants grow up in the same country as their non-immigrant peers. We expect that the absence of firstgeneration barriers to access and advancement will make it easier for descendants' skills premium to result in better workplace outcomes. Therefore, we predict worse outcomes for firstgeneration immigrants, and better outcomes for recent descendants of immigrants, both relative to non-immigrants.

H2: Immigrant generation will influence a) pay, and b) attainment of supervisory positions, such that first-generation immigrants receive worse outcomes and recent descendants of immigrants receive better outcomes, compared to non-immigrants.

Race effect. There is clear and substantial evidence that discrimination against employees of color suppresses workplace outcomes (Roberson, 2019). Much of this discrimination comes in the form of subtle everyday discrimination, such as relatively closed, less friendly communication, or failure to offer assistance to people of color (Deitch et al., 2003). These subtle forms of discrimination can translate into more substantial barriers, such as when managers fail to invite employees of color to join powerful committees, or overlook them for recognition and promotions (Triana, Jayasinghe, \& Pieper, 2015). Theoretical mechanisms for racial discrimination research usually rely on individual cognitions, such as unconscious biases or lay theories of race (Hong, Chao, \& No, 2009), or on social categorizations, such as majority/minority or ingroup/outgroup dynamics (Deitch et al., 2003; Roberson, 2019). 
Beyond the more general downward pressure on workplace outcomes for employees of color, there is also substantial evidence that immigrants of color experience more labor market barriers than white immigrants (Aydemir \& Skuterud, 2005; Fang, Samnani, Novicevic, \& Bing, 2013; Guiliano et al., 2009). For example, employment rates for first generation European immigrants to Canada are more than 10 percentage point higher than those for first generation immigrants from Asia (Ysaad, 2012). Immigrants of color and their recent descendants may seem more 'foreign' to white managers, perpetuating the liability of foreignness (Fang et al., 2013). This occurs in addition to the cognitive and social categorization mechanisms just described, that explain racial barriers in general terms. For this reason, we predict that barriers to entry and advancement will be worse for people of color, resulting in lower levels of workplace outcomes.

H3: People of color will have lower a) pay, and b) attainment of supervisory positions than white people.

Mother tongue effect. There is an alternative explanation for both generation and race effects. Any inferior outcomes experienced by first-generation immigrants of color could instead be explained by barriers for individuals working in a non-native language (Marschan-Piekkari, Welch, \& Welch, 1999; Peltokorpi \& Vaara, 2012, 2014). Individuals working in a non-native language are likely to be less proficient than native speakers, even if their language skills are at a high level (Widdowson, 1998). The mother tongue effect is important enough that professional translators are usually constrained to only translate into their own mother tongue, not the other direction. This effect has been demonstrated among immigrants to the Netherlands, where lower proficiency predicted lower hourly pay, especially for women (Yao \& van Ours, 2015), and in the UK where it had a direct negative effect on pay (Dustmann \& Fabbri, 2003). Fears about 
poor language proficiency could also explain why job applicants are less likely to be contacted after submitting resumes with Asian names; employers who were contacted after making their call-back decisions cited concerns over language as a reason for avoiding applicants with Asian names (Oreopoulos, 2011). Even though multiple languages are a valuable skill for a subset of the workforce who work in internationally-oriented positions, we expect that language barriers are more common, especially for individuals working in a non-native language environment (Brannen, Piekkari, \& Tietze, 2014; Hinds, Neeley, \& Cramton, 2014; Tenzer, Pudelko, \& Harzing, 2014). Thus we expect worse workplace outcomes for individuals who work in a language other than their mother tongue, relative to individuals working in a mother tongue.

H4: Working in a non-native language will have a negative influence on a) pay, and b) attainment of supervisory positions.

Gender effect. Firms are gendered spaces that reflect societal power structures, meaning traditionally male qualities such as competitiveness and dominance are often valued more than traditionally feminine qualities such as nurturing and care for others (Koveshnikov, Tienari, \& Piekkari, 2018). Thus, poor outcomes for women often operate through similar subtle, everyday behaviors as those described for racial discrimination (Roberson, 2019). The theoretical mechanisms are also similar, meaning that mechanisms are commonly explained through socialpsychological theories of intergroup relations, where uncommon characteristics become salient for categorizing individuals (Tajfel \& Turner, 1986).

Beyond the more general downward pressure on women's workplace outcomes, immigrant women are known to have lower pay than their male immigrant counterparts, an effect called the 'double earnings penalty' (Lopez, 2012). Although the gender pay gap persists for women in general, it is exacerbated for immigrant women as a result of factors including the 
double source of discrimination (Lopez, 2012), increased levels of occupational segregation (del Rio \& Alonso-Villar, 2012) and gendered social network patterns that suppress career opportunities for immigrant women (Hagan, 1998). Some immigrant women cope with their limited career opportunities by instead idealizing patriarchal gender roles (Mahalingam et al., 2008). Although these strategies help to improve personal well-being through increased resilience in the face of a double earnings penalty, they do not improve career prospects (Mahalingam et al., 2008). Thus we expect worse outcomes for women than for men. H5: Gender will influence a) pay, and b) attainment of supervisory positions, such that women receive lower outcomes than men.

\section{INSERT TABLE 1 AND FIGURE 1 ABOUT HERE}

\section{Putting it together: Revisiting intersectional effects}

The four direct effect hypotheses (H2-H5) predicted outcomes each demographic dimension independent of others, the most common approach in international business research. To test our intersectional hypothesis (H1), we instead predicted outcomes for groups of people who are themselves members of multiple groups (Mahalingam et al., 2008; McCall, 2005; Warner, 2008). Without a strong theoretical basis for weighting one barrier as larger than the others, the logical default is equal weightings, where each source of barriers is assumed to be similarly strong: being a first-generation immigrant (-1), a person of color (-1), speaking a mother tongue other than the working language (-1), or being female (-1). When combined with the skills premium already described for individuals with an immigrant background $(+1)$, their additive combination across 24 intersectional groups results in a pattern of six different sums, 
ranging from -4 to +1 . We revisit the validity of this additive, equal weightings approach to intersectionality after examining our results.

After controlling for other demographic and organizational factors, we expect the pattern of pay and supervisory positions across intersectional groups will be related to this linear set of sums of barriers. Most groups will receive worse outcomes relative to the referent group (group $\# 20$, sum of 0 ) of white, male, non-immigrants who work in their native languages. At the far right of Figure One, the line above the zero line (group \#24, sum of +1 ) represents our expectation that white, male, descendants of immigrants who work in their native languages will have the highest workplace outcomes, based on the argument that the skills premium only outweighs barriers when no barriers are present. At the far left of Figure One (group \#1, sum of 4), we expect that first-generation immigrant women of color who work in a non-native language will receive the worst outcomes. This approach moves beyond attempts to quantify the impact of being an immigrant; instead we aim to understand the impact of being a first-generation immigrant woman of color whose mother tongue is not English, along with each of the other groups described here.

\section{Individuals in context: Moderating effect of international orientation}

Theoretical arguments about both resources and discrimination help to explain why international organizations may mitigate each of our hypothesized gaps. Following the resources story, the skills and abilities that employees with an immigrant background bring to organizations may be more relevant and valued in internationally-oriented firms. In this context, individuals with an immigrant background may be more likely to have the skills that fit their organizations' needs because organizations that operate across borders naturally benefit from individuals who are skilled at working cross-culturally. This is consistent with findings that 
bicultural professionals were promoted more quickly when employed in cross-cultural roles, relative to individuals who identified primarily with one culture, because the former group outperformed the latter on culture-relevant tasks (Tadmor et al., 2012). In addition, a link has been found between multiculturalism and creativity, but only for culture-relevant tasks (Leung et al., 2008). The culture-relevant nature of tasks within internationally-oriented firms means this may be a particularly relevant context to showcase the skills premium for individuals with an immigrant background.

International firms may also lower barriers for entry and advancement of marginalized employees, referring to employees who are treated as peripheral or insignificant, by recognizing the strategic opportunity to attract talented employees who may be overlooked by domestic firms (Siegel, Pyun, \& Cheon, 2018). Firms with foreign headquarters have been found to be more likely to hire socially excluded groups, such as hiring women in South Korea (Siegel et al., 2018), women and members of lower-status groups in Latin America (Newburry, Gardberg, \& Sanchez, 2014), women and people of color in the U.S. (Newburry, Gardberg, \& Belkin, 2006). We argue that international firms are less bound by domestic stereotypes about underrepresented groups, reducing the degree to which group membership is a barrier.

Referring specifically to the four barriers considered in this paper, first-generation immigrants may find that internationally-oriented firms are less likely to devalue foreign credentials and work experience. As a result of working globally, firms are more likely to have practices and processes in place that facilitate hiring and promoting first-generation immigrants. They may be more skilled at procuring work visas, more likely to accept foreign credentials, have a workplace culture that is accepting of varying levels of language proficiency and hiring practices that emphasize the importance of fit with a diverse clientele (Dietz, Joshi, Esses, 
Hamilton, \& Gabarrot, 2015; Guo \& Al Ariss, 2015). Following a similar line of argumentation, within-firm international movements of employees create environments where it is common and normal to work in a language other than one's mother tongue, and where people of color face less discrimination than they do in domestic firms (Hinds et al., 2014; Newburry et al., 2006). Finally, previous research has already established that internationally-oriented firms can reduce barriers for employing women (Koveshnikov et al., 2018; Newburry et al., 2006; Newburry et al., 2014; Siegel et al., 2018). Therefore, internationally-oriented firms may have more to gain by employing individuals from marginalized groups, and also be less likely to engage in practices that restrict career advancement for first-generation immigrants, women, people of color or individuals whose mother tongue is different from the language of work:

H6: Firm-level international orientation will moderate the relationships proposed in $\mathrm{H} 2-$ $\mathrm{H} 5$, such that the deficit will be smaller within internationally-oriented firms, for: a) firstgeneration immigrants, b) people of color; c) individuals whose mother tongue is not the language of work; and d) women.

\section{METHOD}

We use linked Canadian employee-employer data from Statistics Canada's Workplace and Employment Survey (WES) to examine the relationship between immigrant employees, recent descendants of immigrants, and two dependent variables: pay and attainment of a supervisory position. The multilevel data offers the opportunity to examine employee outcomes while controlling for workplace characteristics, using a nationally representative sample. There are several reasons why Canada is an ideal country for examining workplace outcomes for immigrants and their descendants: It is an immigrant-heavy country with a relatively small population, meaning that $39.4 \%$ of the current Canadian population are first- or second- 
generation immigrants (Statistics Canada, 2015), already slightly higher than the projected 37\% share of the U.S. population in 2050 (Pew Research Center, 2013); It is a developed country with relatively small economic shifts over time, meaning estimates are generally stable; its national policy of multiculturalism makes this country an interesting test case for examining outcomes within a reasonably welcoming political environment. We discuss this last point further in the implications section.

\section{Sample}

The annual data in WES covers the period from 1999-2005 and surveys approximately 6000 firms and 20,000 of those firm's employees each year. WES samples employers by physical location and then employees are sampled from employer provided lists, where trained survey administrators collect data using computer assisted telephone interviews. The survey has a high response rate - approximately $86 \%$ for both firms and employees. The workplace data is an unbalanced longitudinal panel, where employees are re-sampled every second year with some questions asked only in the first year. This design limits the possibility of longitudinal analysis. Instead, our reported results use the 2005 sample of employees, though we re-estimated our main specifications using both the 2003 and 2001 samples of employees to test whether our results were consistent over time. We found no differences in the significance levels or direction of results across the three samples.

The survey design and process of sample selection in WES requires careful consideration when analyzing the data. WES is a stratified design where businesses in Canada were grouped into 252 different strata based on fourteen industry classifications, six regional classifications and three size classifications. The strata were constructed so as to maximize the variation between strata but minimize variation within strata. Once stratified, firms were randomly 
sampled from each stratum. The number of firms sampled from within each strata was determined using Neyman allocation, where more firms are sampled from strata with higher variability and fewer firms from strata with lower variability. This sampling technique implies that some sampled units represent more (and some fewer) segments of the population than others. In order to use this sample to construct population relevant estimates, Statistics Canada calculates a survey weight for each sampled unit based on its probability of selection, sample clustering and stratification and we use these weights in all empirical analysis, following Statistics Canada's recommendations. As a result, our findings are estimates of a nationallyrepresentative sample. Additionally, all of our analysis uses bootstrapping to correct our standard errors for survey design.

\section{Measures}

Immigrant is a binary indicator variable identifying whether or not an employee is a first generation immigrant to Canada $(1=$ immigrant, $0=$ non-immigrant $)$. Individuals were assigned a value of 1 if they indicated that they were born outside of Canada. Within our sample, $18 \%$ of employees are classified as first generation immigrants. This is a reasonable reflection of the Canadian population, as, according to the 2006 census, $19.8 \%$ of the total Canadian population were first generation immigrants, but higher unemployment rates among first generation immigrants, and our sample's exclusion of individuals who have been in Canada less than two years might reasonably be expected to lower the share of first generation immigrants in our sample of employees. Descendant is a binary indicator variable identifying whether or not an employee is a recent descendant of immigrants $(1=$ descendent, $0=$ non-descendant $)$. Individuals were assigned a value of 1 for this variable if they indicated that one or more of their parents or grandparents were from ethnic groups other than "Canadian". In our sample, $40 \%$ of 
employees are classified as descendants, roughly equivalent to second and third generation immigrants. The 2006 Canadian census indicates $17 \%$ of the total population were second generation immigrants, but does not tabulate the share of third generation immigrants. However, Bonikowska (2005) estimates the $3^{\text {rd }}$ generation immigrant population in Canada in 2001 at $22 \%$ of adults 25 years or older. Hence our $40 \%$ value for second and third generation immigrants is roughly consistent with estimates of the working age population of second and third generation immigrants in Canada. The remaining $42 \%$ of our sample indicate their ethnic heritage as "Canadian" and are classified as non-immigrants.

We measure two different workplace outcomes, chosen because employees tend to care deeply about them: pay measured as annual earnings; and attainment of a supervisory position within their firm, based on respondents" yes (1) or no (0) answer to the question, "Do you supervise the work of other employees on a day to day basis?".

We code employees' race by participants' self-identified ethnic origins ${ }^{3}$ using a binary variable where $1=$ person of color and $0=$ white, consistent with how Statistics Canada constructs their visible minority variable. In our sample, $12 \%$ of employees are classified as people of color. The 2006 Canadian Census indicates that $16.2 \%$ of the Canadian population were people of color. Our slightly lower percentage may reflect both a conservative measure and lower representation of people of color in the formal workforce.

We measured the proposed language barrier by assigning a value of 0 for respondents who speak the same language at home as they do at work and 1 for respondents who speak a different language at home as they do at work ( $10.3 \%$ of total, $4.5 \%$ of descendants and $41.4 \%$ of first generation immigrants). Although the language at work for most of Canada is English, many

\footnotetext{
${ }^{3}$ Respondents indicating non-European ethnic origins were classified as people of color.
} 
Francophone workplaces also exist. Measuring the language effect by differences between home and work accommodates both, rather than assuming the language of work is English. Individuals who speak the same language at home and work will experience no language barrier at work. Even though it is possible to be proficient in the workplace language while also speaking a different language at home, the working language is more likely to be spoken with an accent, which has been shown to result in worse employment outcomes (Hosoda \& Stone-Romero, 2010). The WES data does not include a measure of French or English language proficiency. The gender barrier was assessed by assigning a value of 1 for self-identified females (52.6\% of sample), and 0 for males. The WES data does not include other genders.

Our firm-level moderating variable, international orientation, was measured by the percentage of sales coming from outside of Canada (ranges from $0 \%$ to $100 \%$, with a mean of $5.7 \%)$

We controlled for individual-level and firm-level variables in all analyses. At the individual level, we controlled education (a categorical variable ranging from 0 for respondents with a primary school education or less, to 9 for respondents with a Doctorate), age, years of experience in their profession (ranges from 1 to 47, mean of 17.6), occupation (6 categories, controlled using dummy variables $)$, and unionization $(1=$ unionized $)$. At the firm level, control variables were chosen based on their potential to influence the presence and value of employees with an immigrant background. Firm size was measured by the total number of employees, a foreign competition index was calculated using the firm's rating of the level of competition they face from firms outside of Canada (ranges from 0 to 12), and a relative performance index that estimates a firm's performance relative to other firms in their industry (three 5-point scales measuring relative sales, profitability and productivity are summed, resulting in a total range 
from 3 to 15). Industry was controlled through 14 categorical fixed effect variables. Correlations, means and standard deviations are presented in Table 2. All correlations between variables are within the range $[-0.20$ to 0.40$]$, with the exception of age and years of experience, where the correlation is approximately 0.70 .

\section{INSERT TABLE 2 ABOUT HERE}

\section{Analysis}

We used a different survey specific regression model to fit each dependent variable: OLS regression to predict pay and a probit model to predict the attainment of a supervisory position. In both cases, we estimate using appropriate survey weights and bootstrapped standard errors. Our primary estimating equation is specified as follows:

$$
\text { Outcome }_{i}=\alpha+\delta_{i} \text { Immigrant Gen }_{i}+\theta_{i} \text { Barrier }_{i}+\beta_{i} Y_{i}+\beta_{j} X_{j}+\epsilon
$$

where the workplace outcomes of employee $i$, Outcomes ${ }_{i}$, are the natural log of pay or the attainment of a supervisory position, Immigrant Gen is a vector of two binary indicator variables for first generation and later generation immigrants, Barrier is a vector of three different binary indicator variables for gender, race and mother tongue, $Y_{i}$ is a vector of the individual level control variables, and $X_{j}$ is a vector of the firm level control variables. As described below, we later modify our estimating approach by interacting Immigrant Gen and Barrier with the international orientation of the firm and by replacing Immigrant Gen and Barrier with Intersectional Groupings rather than individual characteristics. 


\section{Results}

The effects of each barrier can be seen in Table 3. The first portion (Table 3a) contains the control variables while the second portion (Table 3b) contains the main variables of interest.

\section{INSERT TABLES 3a and 3b ABOUT HERE}

Direct effect results. Our predictions for the race effect (H3a, H3b), the mother tongue effect (H4a, H4b) and the gender effect (H5a, H5b) are fully supported, meaning each of these barriers suppresses both pay and likelihood of attaining a supervisory position. In addition, after holding all else constant, the effect size was larger for gender than for the other barriers. Women earn $13 \%$ less annually and are $3.8 \%$ less likely to attain a supervisory position, people of color earn $8 \%$ less annually and are $0.5 \%$ less likely to attain a supervisory position, and individuals working in a non-native language earn $7.6 \%$ less annually and are $3.2 \%$ less likely to attain a supervisory position. ${ }^{4}$

Results for the immigrant generation effect are mixed. Consistent with $\mathrm{H} 2 \mathrm{a}$ and $\mathrm{H} 2 \mathrm{~b}$, descendants have better outcomes than non-immigrants for both pay and supervisory positions. However, first-generation immigrants only receive worse outcomes than non-immigrants when the other barriers (race, mother tongue and gender) are not controlled. Once those variables are added in models 3-6, first generation immigrants experience better outcomes than nonimmigrants. Holding all else constant, first generation immigrants earn $2.3 \%$ more annually and are $5.4 \%$ more likely to attain a supervisory position, and descendants of immigrants earn $2.9 \%$

\footnotetext{
${ }^{4}$ Marginal effects for the probit model (probability of attaining a supervisory position) were estimated following Greene (1996). For pay, note that the dependent variable is the natural log of annual salary, such that interpreting the marginal effects requires raising $e$ to the power of each coefficient.
} 
more annually and are $4.1 \%$ more likely to attain a supervisory position. This finding demonstrates that immigrant generation is not the primary predictor of workplace outcomes, and must be combined with other factors to build an accurate story.

Moderated results with international orientation. The bottom portion of Table $3 \mathrm{~b}$ interacts our predictor variables with the international orientation of the employee's workplace. Supporting H6a, the interactions between international orientation and both first generation and later generation immigrant are positive and significant, suggesting that internationally-oriented firms may impose fewer barriers and have more to gain by employing individuals with immigrant backgrounds. Holding all else equal, a first generation immigrant working in a firm with no exports (international orientation $=0$ ) will earn an annual salary premium of $3.5 \%$. However, a first generation immigrant in a firm which earns $50 \%$ of its revenue from exports (international orientation $=50$ ) will earn an annual salary premium of $8.4 \%$.

Partially supporting H6b and H6c, the pay deficit for people of color and people working in non-native language is smaller in internationally-oriented firms compared to domestic firms, though there was no significant modifying effect for race or mother tongue on supervisory responsibility. That means holding all else equal, a person of color working in a firm with no exports (international orientation $=0$ ) will earn an annual salary deficit of $8.7 \%$. However, in a firm which earns $50 \%$ of its revenue from exports (international orientation $=50$ ) that deficit shrinks to $3.7 \%$.

Counter to expectations (H6d), international orientation widened the gender gap for both pay and attainment of a supervisory position, rather than reducing it. To check for robustness of our measure of international orientation, we replicated analyses using three alternatives: the percentage of foreign ownership, the foreign competition index, and selecting only firms with 
non-zero values for international orientation. Results remained consistent across all models, indicating these findings do not depend on the specific measure or sample.

Intersectionality results. To test the predicted linear trend across intersectional groups, we next examine the combined effects of all four barriers. The final column of Table 1 presents the mean pay premium or discount predicted by the six different sums of barriers. Supporting H1a we see that these group means form a strictly increasing pattern from the lowest sum of barriers $(-4)$ to the highest $(+1)$. The only group with all four barriers present (first generation immigrant women of color, working in a language other than their mother tongue) has the largest disadvantage in terms of both pay ( $\$ 8310.98 \mathrm{deficit} /$ year) and supervisory responsibility. The five subsequent groups show a linear trend of progressively better outcomes.

As shown in table 4, we test the linear trend by grouping employees based on their sums of barriers, where the group with all four barriers is the omitted category. Consistent with H1a and $\mathrm{H} 1 \mathrm{~b}$, our data support the overall linear trend predicted by an additive, intercategorical model of barriers. As a robustness check, we found that our data did not support an alternative model where each factor was framed as both a privilege and barrier $(+1 /-1)$ rather than our current model that only tests barriers $(0 /-1)$. Thus, we did not find support for a model where being male, white, or working in one's mother tongue each received a weighting of +1 , indicating a boost to workplace outcomes for membership in any of these groups. Despite the overall additive linear trend, some intersectional groups received outcomes much higher or lower than those predicted by their sum of barriers, and these groups merit further examination.

INSERT TABLE 4 ABOUT HERE 
To quantify the magnitude of effects on each of the 24 intersectional groups described in Table 1, we re-estimated our model excluding group 20 (non-immigrant, white men working in their mother tongue, who receive a mean salary of $\$ 37,643$ ) and calculating the pay premium or discount each group receives relative to this reference group ${ }^{5}$. These pay differences control for age, experience, education, occupation and our complete set of firm and industry level control variables. They are presented in the second last column of Table 1, and depicted in Figure 1. All four of the groups who are both people of color and working in a non-native language have very small sample sizes, such that two of these groups (groups 5 and 9, non-immigrant women and men) had pay results that were not significantly different from the referent group. We therefore do not interpret results for groups 5 and 9, and are cautious when interpreting results for groups 12 and 17 (descendant women and men).

Three groups had larger pay premiums than the referent group, all of whom were groups of white men: White, male descendants working in their mother tongue (group 24, premium of \$936); white, male descendants working in a different language (group 22, premium of \$294); and the largest premium of $\$ 2162$ per year went to first-generation white men working in their mother tongue (group 13). In contrast, the three groups receiving the largest pay deficit were all first-generation immigrants working in a non-native language: White women (group 4) received a pay deficit of $\$ 5486$; men of color (group 2) received a pay deficit of $\$ 7152$; and as predicted, women of color (group 1) received the largest pay deficit of $\$ 8311$.

Finally, we examined the difference between predicted and calculated pay in the last two columns of table 1 to discover which groups received outcomes that were not predicted by

\footnotetext{
${ }^{5}$ The OLS regression coefficients indicate the partial derivative of hourly pay with respect to each group, which we then converted to an annual pay premium or discount relative to the reference group based on 1747 hours worked in a year (1747 is the average number of hours Canadians worked in 2005 according to the OECD: https://stats.oecd.org/index.aspx?DataSetCode=ANHRS).
} 
equally-weighted sums of barriers. The most unexpected pay premium $(\$ 4828 /$ year more than predicted by the sum of barriers, group 13) again went to first-generation white men working in their mother tongue. Other unexpected premiums went to white male descendants working in non-native languages (group 22, \$2095 more than predicted) and first-generation women of color working in a mother tongue (group 3, \$2490 more than predicted).

The most unexpected pay deficit ( $\$ 2295 /$ year less than predicted by the sum of barriers, group 18) went to female descendants of color not working in a mother tongue. There was no clear pattern behind the other unexpected deficits, which accrue to male descendants of color working in a non-native language (group 17, \$2175 less than predicted), white female nonimmigrants working in a non-native language (group 11, \$2078 less than predicted), and white female non-immigrants working in their mother tongues (group 16, \$2050 less than predicted). These findings indicate that although the additive pattern can explain overall effects, some groups have workplace outcomes that do not conform to that pattern, and merit further exploration to discover why.

\section{DISCUSSION}

Our results help build theory in three areas: we build on intersectionality research by addressing how different theoretical approaches can be mutually supportive, develop a deeper understanding about how and why internationally-oriented firms reward members of marginalized groups differently than domestic firms, and integrate theory about migrants across disciplines.

Combining intersectionality approaches. Much of the intersectionality research uses an emic, 'deep dive' approach to understanding the distinct experiences among members of one intersectional group (Weaver et al., 2016). This approach is valuable for surfacing unique 
experiences that cannot be revealed by etic or comparative approaches (Tatli \& Özbilgin, 2012). Instead, we draw on an intercategorical approach to reveal patterns across groups (McCall, 2005; Warner, 2008; Weaver et al., 2016). Through this approach, we found overall support for a linear trend based on the assumption of equally-weighted additive barriers, but also discovered that the general trend did not apply to all groups. We would like to highlight two anomalies related to groups with unexpected premiums and penalties.

The first anomaly is that first-generation immigrant status had a surprisingly positive effect on outcomes after controlling for all other barriers. Consider the difference between white, male immigrants working in their mother tongues (group 13), and female immigrants of color who were also working in their mother tongues (group 3). Both groups are first-generation immigrants working in their mother tongues, and both received more pay than predicted by an additive model. However, holding all else equal, the white men received $\$ 6263$ more in annual pay than the women of color, illustrating the combined effect size of race and gender for firstgeneration immigrants. Further exploration tells a better picture of the individuals in each of these two groups. The white male immigrants had a long average tenure in Canada ( $\sim 23$ years) and worked primarily in traditional industries such as mining, oil and gas, and construction. Although the female immigrants of color have a similarly long average tenure in Canada ( $\sim 20$ years), a larger percentage of this group are relatively recent immigrants ( $35 \%$ have been in Canada for 10 years or less, compared to $24 \%$ of all first-generation immigrants). We recommend following up with more qualitative intersectional approaches to understand whether these two groups' different experiences can be explained by tenure, gender or entirely different combinations. 
The second anomaly is that although we started with the assumption of equally weighted barriers, we found that the gender barrier had a bigger impact on outcomes than the others. This unequal weighting was the clearest pattern among our unexpected premiums and deficits: $2 / 3$ of all groups with unexpected pay premiums were male, while $4 / 5$ of all groups with unexpected pay deficits were women. However, we caution researchers from over-interpreting these results, meaning we see both data-driven and epistemological reasons to provisionally retain the assumption of equally weighted barriers. From a data perspective, although gender was a stronger predictor in this sample, its relative strength might not be generalizable to other samples, such as those with less immigrant focus or more female-dominant industries. Epistemologically, the rank-ordering implied by differential weightings of barriers is yet another departure from the intersectional rationale that characteristics must be considered in combination, not in isolation. Despite these cautions, we encourage future research about immigrants to theorize about gender along with immigrant status in their models (beyond including it as a control variable), or risk drawing unfounded conclusions about universal challenges experience by immigrants and their descendants.

Thus, in response to our provocative question about whether an additive model of intersectionality ever holds, our answer is a qualified yes; it can hold, so long as allowances are made for unequally weighted barriers, such as the gender effect, or groups with outlier experiences, such as the positive impact of first-generation status for white men only. We therefore encourage future intersectionality researchers to remain open to the possibility that linear, intercategorical patterns across groups exist simultaneously with open, multiply constituted experiences within groups. Ultimately, we argue that these often oppositional approaches to intersectionality can instead support each other. 
Internationally-oriented firms and marginalized groups. Our firm-level interaction results offer an alternative explanation to current research that claims international firms mitigate downward pressure on outcomes for underrepresented groups by recruiting talented members of these groups as strategic opportunities to build workforce performance, or by importing global human resource practices that support marginalized employees better than local practices (Newburry et al., 2014; Siegel et al., 2018). Instead, we found that the degree to which a firm is international improved outcomes for some marginalized groups (immigrants, people of color, non-native speakers), even while they widened the outcome gap for women relative to men. Although none are large effects, we propose two conditions upon which any interaction effect may depend: It may depend on the domestic marginalization of each group relative to international standards; or on the relative fit between a marginalized group and international business activities.

Related to the domestic marginalization condition, women and lower-status groups tend to be underemployed in South Korea and Latin America relative to international standards. International firms have discovered that they can gain strategic advantage by employing Korean women (Siegel et al., 2018), and Latin American women and lower-status groups (Newburry et al., 2014). Although our country context of Canada exhibits a pay gap between men and women (Morissette \& Sultan, 2013), the gap is relatively small by international standards, reducing the benefit offered by international firms' practices relative to domestic ones. Thus, it may not be the case that internationally-oriented firms mitigate downward pressure on workplace outcomes for all underrepresented groups, but only for groups where international standards and practices are generally better than those offered domestically. For example, research conducted in France found that most firms had not adopted international HR standards related to valuing immigrant 
employees (Guo \& Al Ariss, 2015). In this environment, internationally-oriented firms may have an opportunity to differentiate their HR practices from those of local firms.

Related to the relative fit condition, the additional resources attributed to individuals with an immigrant background are a particularly good fit for internationally-oriented firms; Individuals who belong to more than one culture have been found to have advantages primarily when tasks are culture-relevant, such as creativity within cross-cultural contexts (Cheng, Sanchez-Burks, \& Lee, 2008), cross-cultural network development and boundary-spanning (Fitzsimmons et al., 2017; Jang, 2017). It is therefore not surprising that internationally-oriented firms are especially good places for individuals with an immigrant background to work. Yet even in these firms, the interaction effect is not large, since immigrants are rarely recruited strategically for their international insights (Hajro et al., 2018). The partial mitigating effects for employees of color and those working in a non-native language can also be explained by the relevance of these demographic characteristics for internationally-oriented firms; in environments where linguistic diversity and international mobility are both common, immigrants are less likely to stand out for belonging to either of these groups.

Crossing disciplines. Finally, we developed our hypotheses by integrating economic arguments about labor market barriers that exert downward pressures on workplace outcomes (Algan et al., 2010; Baker \& Benjamin, 1994; Borjas, 1994; Dustmann \& Fabbri, 2003; Guiliano et al., 2009; Guo \& Al Ariss, 2015; Mahalingam et al., 2008; Morissette \& Sultan, 2013; Oreopoulos, 2011; Yao \& van Ours, 2015) with international management arguments about additional resources that exert upward pressures on workplace outcomes (Barner-Rasmussen et al., 2014; Brannen \& Thomas, 2010; Fitzsimmons et al., 2017; Fitzsimmons et al., 2011; Tadmor et al., 2012). Such an interdisciplinary perspective provides complementary macro- and micro- 
views on the oppositional pressures that both help and hinder the integration of the new demographic in the workplace. Our findings demonstrate that it is inadequate to explain unequal outcomes for immigrants and their descendants entirely through either structural or individuallevel arguments. Instead, both play important roles, where the relative weighting of oppositional pressures matters for predicting material differences in employees' outcomes. Economic arguments about structural barriers that limit individuals' access or advancement in the workplace would be more accurate if they also allowed the possibility that individuals with an immigrant background may have additional human resource value beyond that of nonimmigrants. International management arguments about additional resources arising from a multicultural background would be more accurate if they accounted for the substantial structural barriers limiting the possibility for many employees to be recognized for their contributions. Our interdisciplinary approach allowed us to identify and quantify evidence for oppositional pressures stemming from both resources and barriers.

\section{Practical implications}

Our results suggest practices that should be considered by both organizations and by policy-makers. First, organizational practices designed to improve workforce diversity often select single diversity categories to promote, such as minority recruitment programs that focus on either race or gender. Results from this study highlight a problem with this approach, in that dividing a workforce along single categories masks variability among category members, which can be significant. For example, employee resource groups (ERGs) are designed to create supportive environments for minority groups. Yet, they can inadvertently make individuals with multiple barriers feel even more isolated, such as when ERGs exist for female employees (but are primarily populated by white women) and for employees from a range of racial groups (but 
are primarily populated by men). When intersectional groups represent a very small percentage of the workforce, it is even more important to create a network where they can connect with others who share both or all of their categories.

The dangers of single-category approaches can also be seen when anti-immigrant sentiment is stirred by media that claims immigrants fare better economically than nonimmigrants. We ran a model that compared all individuals with an immigrant background to all non-immigrants, and found that the former group had superior outcomes to the latter when other demographic characteristics were not controlled. However, this paper's results show that immigrants' superior outcomes were almost entirely attributable to groups who are not normally the target of anti-immigrant sentiment, such as white men immigrating to Canada from the U.S., the UK, France or Australia. Even though there were only 3 groups out of 24 that received superior outcomes, they represent around $37 \%$ of individuals with an immigrant background in our sample, meaning the sheer size of these relatively privileged groups overwhelms others, resulting in inaccurate conclusions about immigrants as a whole.

Second, many immigrant-receiving countries have points-based immigration policies, where a majority of immigrants are selected on the basis of skills and education. Firms in industries such as technology and medicine rely on immigrants to provide skills underrepresented in non-immigrant employees. However, our results indicate that firms undervalue these skills when present among female immigrants or immigrants of color. On their own, points-based immigration systems are inadequate to ensure immigrants thrive in their careers after arrival, because the latter part of the process depends on firms recognizing and valuing immigrants' human capital (Friedberg, 2000). Governments with points-based 
immigration policies should implement systems that encourage firms to recognize immigrants' skills, regardless of other demographic characteristics.

\section{Limitations}

We did not have access to a measure of proficiency in the working language. This might be an even better predictor of outcomes than mother tongue. Cross-sectional data mean we cannot follow individuals over time. Despite this limitation, the direction of relationships can only run from demographic characteristics to workplace outcomes, not the other way around. Nonetheless, it is possible that an alternative factor related to demographics predicted workplace performance. For example, from 1981 to 2001 , up to $30 \%$ of the pay deficit experienced by immigrants to Canada could be explained by compositional shifts across immigrant cohorts as immigrant source countries shifted away from Europe toward Asia (Aydemir \& Skuterud, 2005).

Our data come from a single year in the mid 2000s. Although we found consistent results for the previous four years of the WES survey, and we control for age and experience, it is possible that some of these relationships change slowly over time, such that relationships are different for different waves of immigrants (Borjas, 1994). For example, immigrants tend to move in cohorts, where Canada's oldest immigrants were primarily from the UK, then other Europeans, followed by major cohorts from Japan and China (Kelley \& Trebilcock, 1998). The earliest Chinese immigrants in the late 1800s and early to mid 1900s were mostly laborers who mostly worked in deplorable conditions. More recently, Chinese immigrants tend to be highly educated professionals. This change over time would not show up in workplace employment census data until the children of modern immigrants reach working age. Therefore, it is possible that our findings about the labor market deficit for Asian-Canadians might not exist for the descendants of current immigrants. 
Finally, we are unable to identify which individuals in our sample were admitted to Canada as refugees. Refugees currently represent around 13\% of Canadian immigrants (IRCC 2017), and often experience additional barriers to labor market entry, related to the trauma they experienced in their home countries. While economic migrants are usually trying to work at positions where they can use their skills, for some refugees, the goal may be to survive until it is safe to return to their home countries, and recover from trauma (United Nations, 2016).

\section{CONCLUSION}

This paper shows the value of zooming out to test overall patterns and zooming in to discover anomalies to those patterns. Although our overall results support the immigrant story about first generation immigrants who sacrifice for the sake of their children, our intercategorical patterns show that hopeful story masks inequality between immigrant groups. Inequality among members of the workforce hurts individuals who are not valued for their contributions, hurts organizations which fail to benefit from employee skills and abilities, and hurts nations which fail to capitalize on the contributions of immigrants and their descendants.

Despite rapid growth in numbers, immigrants have been called the "invisible men and women in diversity research" (Bell, Kwesiga, \& Berry, 2010: 177) and the "forgotten minority" (Binggeli, Dietz, \& Krings, 2013), because they are so often undervalued and understudied. If this growing workplace demographic continues to be both invisible and forgotten, then organizations are suffering a significant missed opportunity by not leveraging the valuable skills already present in their workforces. When nations and organizations take steps to lower barriers for the most marginalized groups, we hope immigrants and their descendants can move over time from being invisible to being recognized as valuable. 


\section{REFERENCES}

Algan, Y., Dustmann, C., Glitz, A., \& Manning, A. 2010. The economic situation of first- and second-generation immigrants in France, Germany and the United Kingdom. The Economic Journal, 120(542): F4-F30.

Anthias, F., \& Yuval-Davis, N. 1983. Contextualizing feminism: Gender, ethnic and class divisions. Feminist Review, 15(62-75): 62.

Aydemir, A., \& Skuterud, M. 2005. Explaining the deteriorating entry earnings of Canada's immigrant cohorts, 1966-2000. Canadian Journal of Economics, 38(2): 641-672.

Baker, M., \& Benjamin, D. 1994. The performance of immigrants in the Canadian labor market. Journal of Labor Economics, 12(3): 369-405.

Barner-Rasmussen, W., Ehrnrooth, M., Koveshnikov, A., \& Mäkelä, K. 2014. Cultural and language skills as resources for boundary spanning within the MNC. Journal of International Business Studies, 45(7): 886-905.

Bell, M. P., Kwesiga, E. N., \& Berry, D. P. 2010. Immigrants: The new 'invisible men and women' in diversity research. Journal of Managerial Psychology, 25(2): 177-188.

Benet-Martínez, V. 2010. Multiculturalism: Culture, social and personality processes. In K. Deaux, \& M. Snyder (Eds.), Oxford Handbook of Personality and Social Psychology: 623-648. New York, NY: Oxford Press.

Berry, J. W., Phinney, J. S., Sam, D. L., \& Vedder, P. 2006. Immigrant youth: Acculturation, identity and adaptation. Applied Psychology: An International Review, 55(3): 303-332.

Binggeli, S., Dietz, J., \& Krings, F. 2013. Immigrants: A forgotten minority. Industrial and Organizational Psychology, 6: 112-118. 
Borjas, G. J. 1994. The Economics of Immigration. Journal of Economic Literature, 32(December): 1667-1717.

Brannen, M. Y., Piekkari, R., \& Tietze, S. 2014. The multifaceted role of language in international business: Unpacking the forms, functions and features of a critical challenge to MNC theory and performance. Journal of International Business Studies, 45(5): 495507.

Brannen, M. Y., \& Thomas, D. C. 2010. Bicultural individuals in organizations: Implications and opportunity. International Journal of Cross Cultural Management, 10(1): 5-16.

Bratsberg, B., Ragan Jr., J. F., \& Nasir, Z. M. 2002. The effect of naturalization on wage growth: A panel study of young male immigrants. Journal of Labor Economics, 20(3): 568-597.

Cerdin, J.-L., Dine, M. A., \& Brewster, C. 2014. Qualified immigrants' success: Exploring the motivation to migrate and to integrate. Journal of International Business Studies, 45(2): 151-168.

Cheng, C.-Y., Lee, F., Benet-Martínez, V., \& Huynh, Q.-L. 2014. Variations in multicultural experience: Influence of bicultural identity integration on socio-cognitive processes and outcomes. In V. Benet-Martínez, \& Y.-Y. Hong (Eds.), The Oxford Handbook of Multicultural Identity: 276-299. New York: Oxford.

Cheng, C.-Y., Sanchez-Burks, J., \& Lee, F. 2008. Connecting the dots within: Creative performance and identity integration. Psychological Science, 19: 1178-1184.

Crenshaw, K. 1991. Mapping the margins: Intersectionality, identity politics, and violence against women of color. Stanford Law Review, 43: 1241-1299. 
Deitch, E. A., Barsky, A., Butz, R. M., Chan, S., Brief, A. P., \& Bradley, J. C. 2003. Subtle Yet Significant: The Existence and Impact of Everyday Racial Discrimination in the Workplace. Human Relations, 56(11): 1299-1324.

del Rio, C., \& Alonso-Villar, O. 2012. Occupational segregation of immigrant women in Spain. Feminist Economics, 18(2): 91-123.

Dietz, J., Joshi, C., Esses, V. M., Hamilton, L. H., \& Gabarrot, F. 2015. The skill paradox: Explaining and reducing employment discrimination against skilled immigrants. The International Journal of Human Resource Management, 26(10): 1318-1334.

Dill, B. T. 1983. Race, class and gender: Prospects for an inclusive sisterhood. Feminist Studies, 9: $131-150$.

Dustmann, C., \& Fabbri, F. 2003. Language proficiency and labour market performance of immigrants in the UK. The Economic Journal, 113(July): 695-717.

Edwards, P., \& Ram, M. 2006. Surviving on the margins of the economy: Working relationships in small, low-wage firms. Journal of Management Studies, 43(4): 895-916.

Fang, T., Samnani, A.-K., Novicevic, M. M., \& Bing, M. N. 2013. Liability-of-foreignness effects on job success of immigrant job seekers. Journal of World Business, 48(1): 98109.

Felski, R. 1997. The Doxa of Difference. Signs: Journal of women in culture and society, 23: $1-21$.

Fitzsimmons, S. R. 2013. Multicultural Employees: A framework for understanding how they contribute to organizations. Academy of Management Review, 38(4): 525-549. 
Fitzsimmons, S. R., Liao, Y., \& Thomas, D. C. 2017. From crossing cultures to straddling them: An empirical examination of outcomes for multicultural employees. Journal of International Business Studies, 48: 63-89.

Fitzsimmons, S. R., Miska, C., \& Stahl, G. 2011. Multicultural employees: Global business' untapped resource. Organizational Dynamics, 40(3): 199-206.

Friedberg, R. M. 2000. You can't take it with you? Immigrant assimilation and the portability of human capital. Journal of labor economics, 18(2): 221-251.

Guiliano, L., Levine, D. I., \& Leonard, J. 2009. Manager race and the race of new hires. Journal of Labor Economics, 27(4): 589-631.

Guo, C., \& Al Ariss, A. 2015. Human resource management of international migrants: Current theories and future research. The International Journal of Human Resource Management, 26(10): 1287-1297.

Hagan, J. M. 1998. Social networks, gender, and immigrant incorporation: Resources and constraints. American Sociological Review, 63(1): 55-67.

Hajro, A., Zilinskaite, M., \& Stahl, G. K. 2018. Acculturation of Highly-Qualified Migrants in the Workplace. Journal of Management Studies Conference - Diversity Perspective on Management, Boston, United States/USA, 17.04-20.04

Hancock, A.-M. 2007. When multiplication doesn't equal quick addition: Examining intersectionality as a research paradigm. Perspectives on Politics, 5: 63-79.

Hinds, P. J., Neeley, T. B., \& Cramton, C. D. 2014. Language as a lightning rod: Power contests, emotion regulation, and subgroup dynamics in global teams. Journal of International Business Studies, 45(5): 536. 
Hong, Y.-Y., Chao, M. M., \& No, S. 2009. Dynamic interracial intercultural processes: The role of lay theories of race. Journal of Personality, 77: 1283-1309.

Hosoda, M., \& Stone-Romero, E. 2010. The effects of foreign accents on employment-related decisions. Journal of Managerial Psychology, 25(2): 113-132.

IRCC (Immigration, Refugees and Citizenship Canada). 2017. Supplementary Information 20182020 Immigration Levels Plan. Ottawa: Government of Canada.

Jang, S. 2017. Cultural Brokerage and Creative Performance in Multicultural Teams. Organization Science, 28(6): 993-1009.

Kelley, N., \& Trebilcock, M. J. 1998. The Making of the Mosaic: A history of Canadian immigration policy. Toronto: University of Toronto Press.

Koveshnikov, A., Tienari, J., \& Piekkari, R. 2018. Gender in international business journals: A review and conceptualization of MNCs as gendered social spaces. Journal of World Business, 54(1): 37-53.

Leung, A. K.-y., Maddux, W. W., Galinsky, A. D., \& Chiu, C.-y. 2008. Multicultural experience enhances creativity. American Psychologist, 63(3): 169-181.

Lopez, M. J. 2012. Skilled Immigrant Women in the US and the Double Earnings Penalty. Feminist Economics, 18(1): 99-134.

Lücke, G., Kostova, T., \& Roth, K. 2014. Multiculturalism from a cognitive perspective: Patterns and implications. Journal of International Business Studies, 45(2): 169-190.

Mahalingam, R., Balan, S., \& Haritatos, J. 2008. Engendering immigrant psychology: An intersectionality perspective. Sex Roles, 59: 326-336.

Markus, H. R. 1977. Self-schemata and processing information about the self. Journal of Personality and Social Psychology, 35(2): 63-78. 
Markus, H. R., \& Kitayama, S. 1991. Culture and the self: Implications for cognition, emotion and motivation. Psychological Review, 98(2): 224-253.

Marschan-Piekkari, R., Welch, D., \& Welch, L. 1999. In the shadow: The impact of language on structure, power and communication in the multinational. International Business Review, 8(4): 421-440.

McBride, A., Hebson, G., \& Holgate, J. 2015. Intersectionality: Are we taking enough notice in the field of work and employment relations? . Work, Employment and Society, 29(2): $331-341$.

McCall, L. 2005. The complexity of intersectionality. Signs: Journal of women in culture and society, 30(3): 1771-1800.

Morissette, R., \& Sultan, R. 2013. Twenty Years in the Careers of Immigrant and Native-born Workers, Economic Insights: Statistics Canada

Newburry, W., Gardberg, N. A., \& Belkin, L. 2006. Organizational attractiveness is in the eye of the beholder: The interaction of demographic characteristics with foreignness. Journal of International Business Studies, 37: 666-686.

Newburry, W., Gardberg, N. A., \& Sanchez, J. I. 2014. Employer attractiveness in Latin America: The association among foreignness, internationalization and talent recruitment. Journal of International Management, 20: 327-344.

Nguyen, A.-M. T. D., \& Benet-Martínez, V. 2013. Biculturalism and adjustment: A metaanalysis. Journal of Cross Cultural Psychology, 44(1): 122-159.

OECD. 2003. Glossary of Statistical Terms: Immigrant Population, Vol. 2019: OECD Statistics Portal. 
Oreopoulos, P. 2011. Why do skilled immigrants struggle in the labor market? A field experiment with thirteen thousand resumes. American Economic Journal: Economic Policy, 3(4): 148-171.

Özbilgin, M., Beauregard, A., Tatli, A., \& Bell, M. P. 2015. Work-Life, Diversity and Intersectionality: A Critical Review and Research Agenda. International Journal of Management Reviews, 13(2): 177-198.

Peltokorpi, V., \& Vaara, E. 2012. Language policies and practices in wholly owned foreign subsidiaries: A recontextualization perspective. Journal of International Business Studies, 43(9): 808-833.

Peltokorpi, V., \& Vaara, E. 2014. Knowledge transfer in multinational corporations: Productive and counterproductive effects of language-sensitive recruitment. Journal of International Business Studies, 45(5): 600-622.

Pew Research Center. 2013. Second-Generation Americans: A portrait of the adult children of immigrants. Washington, D.C.

Roberson, Q. M. 2019. Diversity in the Workplace: A review, synthesis, and future research agenda. Annual Review of Organizational Psychology and Organizational Behavior, 6: 69-88.

Sayer, A. 1997. Essentialism, Social Constructionism and Beyond. Sociological Review, 45(3): 453-487.

Siegel, J., Pyun, L., \& Cheon, B. Y. 2018. Multinational firms, labor market discrimination, and the capture of outsider's advantage by exploiting the social divide. Administrative Science Quarterly. 
Statistics Canada. 2015. Generation Status: Canadian-born children of immigrants, Vol. 2015: Statistics Canada.

Stoyanov, S., Woodward, R., \& Stoyanova, V. 2018. Simple Word of Mouth or Complex Resource Orchestration for Overcoming Liabilities of Outsidership. Journal of Management, 44(8): 3151-3175.

Tadmor, C. T., Galinsky, A. D., \& Maddux, W. W. 2012. Getting the most out of living abroad: Biculturalism and integrative complexity as key drivers of creative and professional success. Journal of Personality and Social Psychology, 103(3): 520-542.

Tajfel, H., \& Turner, J. 1986. The social identity theory of intergroup behavior. In S. Worchel, \& W. Austin (Eds.), Psychology of Intergroup Relations: 7-24. Chicago, IL: Nelson-Hall.

Tatli, A., \& Özbilgin, M. 2012. Surprising intersectionalities of inequality and privilege: the case of the arts and cultural sector. Equality, Diversity and Inclusion: An International Journal, 31(3): 249-265.

Tenzer, H., Pudelko, M., \& Harzing, A.-W. 2014. The impact of language barriers on trust formation in multinational teams. Journal of International Business Studies, 45(5): 508535.

Triana, M. d. C., Jayasinghe, M., \& Pieper, J. R. 2015. Perceived workplace racial discrimination and its correlates: A meta-analysis. Journal of Organizational Behavior, 36(4): 491-513.

United Nations. 2013. International Migration Report: Department of Economic and Social Affairs, Population Division.

United Nations. 2016. International Migration Report 2015: Highlights: Department of Economic and Social Affairs, Population Division. 
Vora, D., Martin, L., Fitzsimmons, S. R., Pekerti, A., Lakshman, C., \& Raheem, S. in press. Multiculturalism within individuals: A review, critique, and agenda for future research. Journal of International Business Studies.

Warner, L. R. 2008. A best practices guide to intersectional approaches in psychological research. Sex Roles, 59: 454-463.

Weaver, K., Crayne, M. P., \& Jones, K. S. 2016. I-O at a Crossroad: The value of an intersectional research approach. Industrial and Organizational Psychology, 9: 197-206.

Widdowson, H. G. 1998. Communication and community: The pragmatics of ESP. English for Specific Purposes, 17(1): 3-4.

Wilson, K. L., \& Portes, A. 1980. Immigrant enclaves: An analysis of the labor market experiences of Cubans in Miami. American Journal of Sociology, 86(2): 295-319.

Yao, Y., \& van Ours, J. C. 2015. Language skills and labor market performance of immigrants in the Netherlands. Labour Economics, 34(June): 76-85.

Ysaad, L. 2012. The Immigrant Labour Force Analysis Series, 2008-2011. Statistics Canada, Labour Statistics Division, 71-606-X(6).

Zikic, J. 2015. Skilled migrants' career capital as a source of competitive advantage: Implications for strategic HRM. The International Journal of Human Resource Management, 26: $1360-1381$. 
Figure 1: Patterned hypotheses based on sum of barriers for each group (orange line) against pay results (blue bars)

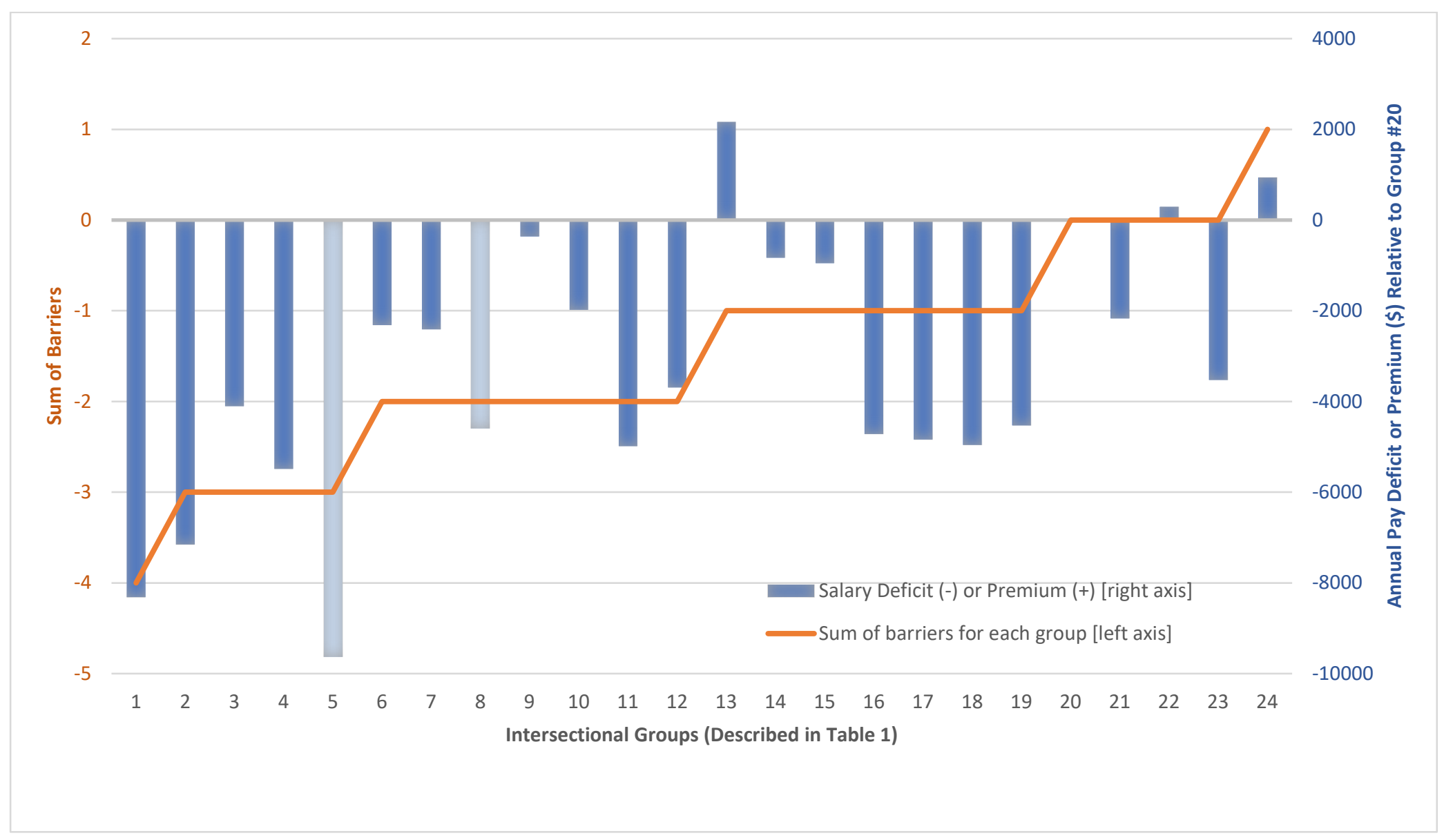

Note: The zero line represents a salary of $\$ 37,643$ for the referent group (group \#20) of non-immigrant (0) white $(0)$ men $(0)$ who work in their native languages (0). All other groups' predicted outcomes are in comparison to this group. Results for groups 5 and 9 are displayed in lighter blue to indicate their pay results were not significantly different from the referent group. 
Table 1: Sum of barriers and pay findings across intersectional groups.

\begin{tabular}{|c|c|c|c|c|c|c|c|c|}
\hline$\#$ & Sum $^{b}$ & $\begin{array}{c}\text { \% of } \\
\text { sample }\end{array}$ & $\begin{array}{c}\text { Immigrant } \\
\text { generation } \\
\text { First }(-1) \\
\text { Non-immigrant }(0) \\
\text { Descendant }(+1) \\
\end{array}$ & $\begin{array}{l}\text { Race } \\
\text { POCa (-1) } \\
\text { white (0) }\end{array}$ & $\begin{array}{c}\text { Other }(-1) \\
\text { Working language }(0)\end{array}$ & $\begin{array}{c}\text { Female }(-1) \\
\text { Male }(0)\end{array}$ & $\begin{array}{c}\text { Results }^{\mathbf{c}} \\
\text { Annual pay } \\
\text { premium or } \\
\text { deficit }\end{array}$ & $\begin{array}{c}\text { Predicted group } \\
\text { mean pay } \\
\text { premium or } \\
\text { discount }^{\mathrm{d}}\end{array}$ \\
\hline 1. & -4 & $2.2 \%$ & First & POC & Other & Female & $-\$ 8310.98 * *$ & $-\$ 8310.98$ \\
\hline 2. & -3 & $2.3 \%$ & First & POC & Other & Male & $-\$ 7152.39 * *$ & \multirow{4}{*}{$-\$ 6591.87$} \\
\hline 3. & -3 & $2.3 \%$ & First & POC & Working language & Female & $-\$ 4101.58 * *$ & \\
\hline 4. & -3 & $1.2 \%$ & First & white & Other & Female & $-\$ 5486.31 * *$ & \\
\hline 5. & -3 & $<0.5 \%$ & Non-immigrant & POC & Other & Female & $-\$ 9627.21$ & \\
\hline 6. & -2 & $1.8 \%$ & First & $\mathrm{POC}$ & Working language & Male & $-\$ 2313.19 * *$ & \multirow{7}{*}{$-\$ 2903.72$} \\
\hline 7. & -2 & $1.1 \%$ & First & white & Other & Male & $-\$ 2410.17^{* *}$ & \\
\hline 8. & -2 & $3.6 \%$ & First & white & Working language & Female & $-\$ 4591.01 * *$ & \\
\hline 9. & -2 & $<0.5 \%$ & Non-immigrant & POC & Other & Male & $-\$ 361.52$ & \\
\hline 10. & -2 & $0.6 \%$ & Non-immigrant & POC & Working language & Female & $-\$ 1976.77^{* *}$ & \\
\hline 11. & -2 & $0.8 \%$ & Non-immigrant & white & Other & Female & $-\$ 4981.33^{* *}$ & \\
\hline 12. & -2 & $<0.5 \%$ & Descendant & $\mathrm{POC}$ & Other & Female & $-\$ 3692.04 * *$ & \\
\hline 13. & -1 & $3.5 \%$ & First & white & Working language & Male & $\$ 2161.64 * *$ & \multirow{7}{*}{$-\$ 2666.31$} \\
\hline 14. & -1 & $0.5 \%$ & Non-immigrant & POC & Working language & Male & $-\$ 829.61 * *$ & \\
\hline 15. & -1 & $0.8 \%$ & Non-immigrant & white & Other & Male & $-\$ 950.42^{*}$ & \\
\hline 16. & -1 & $20.9 \%$ & Non-immigrant & white & Working language & Female & $-\$ 4716.35^{* *}$ & \\
\hline 17. & -1 & $<0.5 \%$ & Descendant & POC & Other & Male & $-\$ 4841.13^{* *}$ & \\
\hline 18. & -1 & $1.4 \%$ & Descendant & POC & Working language & Female & $-\$ 4961.21 * *$ & \\
\hline 19. & -1 & $0.8 \%$ & Descendant & white & Other & Female & $-\$ 4527.07^{* *}$ & \\
\hline 20. & 0 & $16.8 \%$ & Non-immigrant & white & Working language & Male & Reference $^{\mathbf{c}}$ & Reference \\
\hline 21. & 0 & $1.0 \%$ & Descendant & POC & Working language & Male & $-\$ 2169.54^{* *}$ & \multirow{3}{*}{$-\$ 1800.22$} \\
\hline 22. & 0 & $0.7 \%$ & Descendant & white & Other & Male & $\$ 294.33 * *$ & \\
\hline 23. & 0 & $18.9 \%$ & Descendant & white & Working language & Female & $-\$ 3525.46^{* *}$ & \\
\hline 24. & +1 & $17.7 \%$ & Descendant & white & Working language & Male & $\$ 936.26^{* *}$ & $\$ 936.26$ \\
\hline
\end{tabular}


Notes: Grey shaded cells denote a barrier (-1). Bolded text in a cell denotes the hypothesized skills premium. a. POC refers to People of Color. b. These are the values used in the linear test of pay and attainment of supervisory positions across groups (H5). c. ${ }^{*} p<.05, * * p<.01$ relative to the referent group salary of $\$ 37,643$ for white, male, non-immigrants who work in their native languages (group 20, weighting $=0$ ): A negative value indicates a pay deficit for this group relative to the referent group; A non-significant value indicates this group receives pay that are not significantly different from the referent group; A positive value indicates the pay premium this group receives relative to the referent group. d. Predicted means based on sum of barriers. 
Table 2

Correlations, means and standard deviations

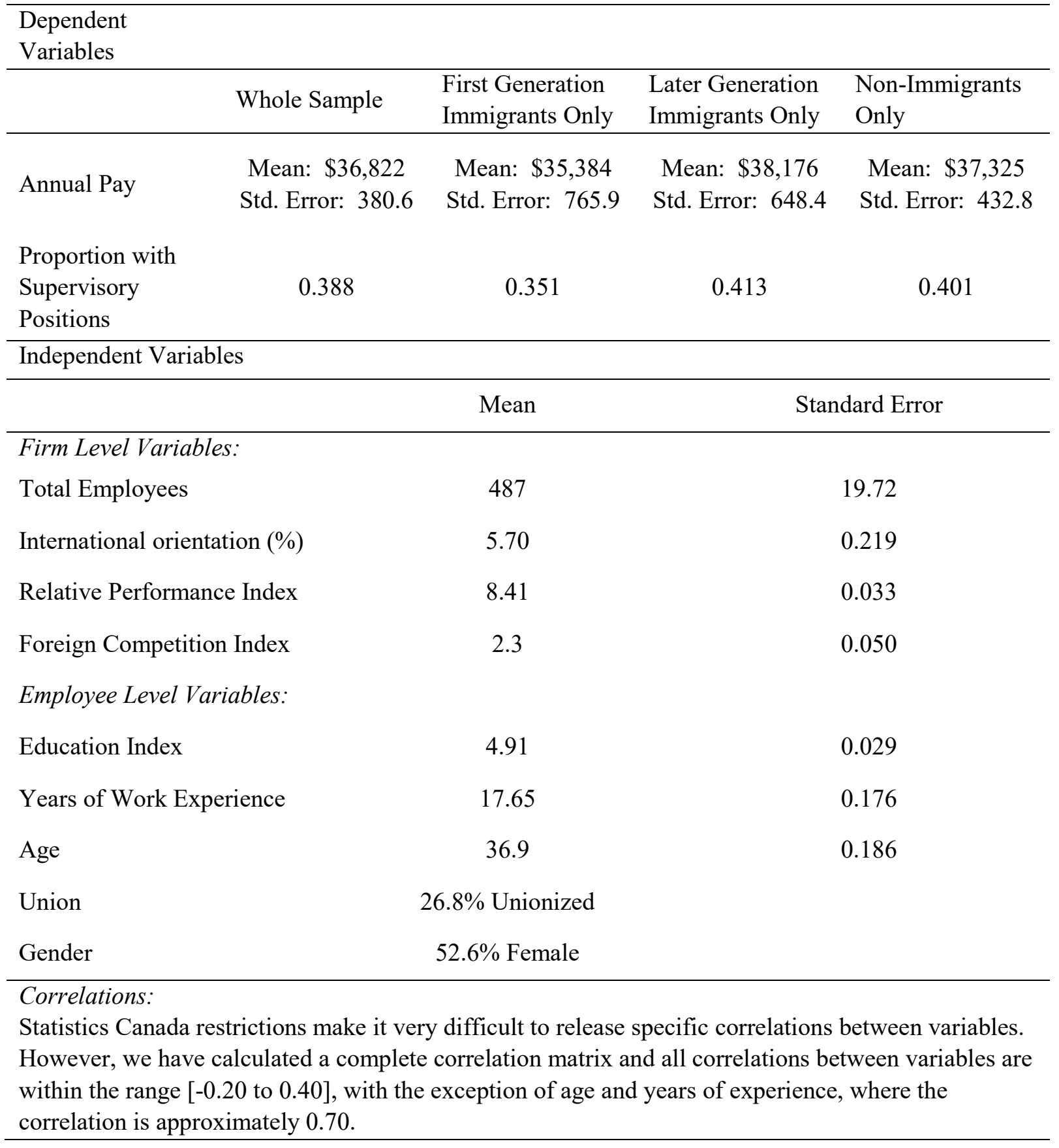


Table 3a - Control Variables' impact on pay and attainment of a supervisory position

\begin{tabular}{|c|c|c|c|c|c|c|}
\hline Dependent Variable: & Pay & $\begin{array}{c}\text { Supervisory } \\
\text { Position }\end{array}$ & Pay & $\begin{array}{c}\text { Supervisory } \\
\text { Position }\end{array}$ & Pay & $\begin{array}{c}\text { Supervisory } \\
\text { Position }\end{array}$ \\
\hline & Model 1 & Model 2 & Model 3 & Model 4 & Model 5 & Model 6 \\
\hline \multicolumn{7}{|l|}{ Individual control variables: } \\
\hline Education Index & $\begin{array}{c}0.053 * * \\
(0.001)\end{array}$ & $\begin{array}{c}0.024 * * \\
(0.002)\end{array}$ & $\begin{array}{c}0.054 * * \\
(0.001)\end{array}$ & $\begin{array}{c}0.025 * * \\
(0.002)\end{array}$ & $\begin{array}{c}0.055 * * \\
(0.001)\end{array}$ & $\begin{array}{c}0.025 * * \\
(0.002)\end{array}$ \\
\hline Years of Experience & $\begin{array}{c}0.009 * * \\
(0.001)\end{array}$ & $\begin{array}{c}0.016 * * \\
(0.005)\end{array}$ & $\begin{array}{c}0.007 * * \\
(0.001)\end{array}$ & $\begin{array}{c}0.014 * * \\
(0.005)\end{array}$ & $\begin{array}{c}0.007 * * \\
(0.001)\end{array}$ & $\begin{array}{c}0.014 * * \\
(0.005)\end{array}$ \\
\hline Age & $\begin{array}{l}0.001 * * \\
(0.0001)\end{array}$ & $\begin{array}{c}-0.008 * * \\
(0.0005)\end{array}$ & $\begin{array}{l}0.002 * * \\
(0.0001)\end{array}$ & $\begin{array}{c}-0.007 * * \\
(0.0005)\end{array}$ & $\begin{array}{l}0.002 * * \\
(0.0001)\end{array}$ & $\begin{array}{l}-0.007 * * \\
(0.0005)\end{array}$ \\
\hline Unionized $=1$ & $\begin{array}{c}0.042 * * \\
(0.003)\end{array}$ & $\begin{array}{c}-0.322 * * \\
(0.009)\end{array}$ & $\begin{array}{c}0.029 * * \\
(0.003)\end{array}$ & $\begin{array}{c}-0.333 * * \\
(0.009)\end{array}$ & $\begin{array}{c}0.030 * * \\
(0.003)\end{array}$ & $\begin{array}{c}-0.334 * * \\
(0.009)\end{array}$ \\
\hline Occupation Fixed Effects & Yes & Yes & Yes & Yes & Yes & Yes \\
\hline \multicolumn{7}{|l|}{ Firm control variables: } \\
\hline Size (employees) & $\begin{array}{c}0.046 * * \\
(0.001)\end{array}$ & $\begin{array}{c}0.010 * * \\
(0.002)\end{array}$ & $\begin{array}{c}0.045 * * \\
(0.001)\end{array}$ & $\begin{array}{c}0.009 * * \\
(0.002)\end{array}$ & $\begin{array}{c}0.045 * * \\
(0.001)\end{array}$ & $\begin{array}{c}0.010 * * \\
(0.002)\end{array}$ \\
\hline International orientation & $\begin{array}{l}0.001 * * \\
(0.0001)\end{array}$ & $\begin{array}{l}-0.001 * \\
(0.0003)\end{array}$ & $\begin{array}{l}0.002 * * \\
(0.0001)\end{array}$ & $\begin{array}{l}-0.001 * * \\
(0.0002)\end{array}$ & $\begin{array}{l}0.003 * * \\
(0.0001)\end{array}$ & $\begin{array}{l}-0.0001 \\
(0.0003)\end{array}$ \\
\hline Foreign Competition Index & $\begin{array}{c}0.009 * * \\
(0.0005)\end{array}$ & $\begin{array}{l}-0.002 \\
(0.001)\end{array}$ & $\begin{array}{l}0.010 * * \\
(0.0006)\end{array}$ & $\begin{array}{l}-0.001 \\
(0.001)\end{array}$ & $\begin{array}{l}0.009 * * \\
(0.0005)\end{array}$ & $\begin{array}{l}-0.002 \\
(0.001)\end{array}$ \\
\hline Relative Performance Index & $\begin{array}{r}-0.005 * * \\
(0.0005)\end{array}$ & $\begin{array}{c}-0.010 * * \\
(0.002)\end{array}$ & $\begin{array}{c}-0.005 * * \\
(0.0005)\end{array}$ & $\begin{array}{c}-0.010 * * \\
(0.002)\end{array}$ & $\begin{array}{l}-0.005 * * \\
(0.0005)\end{array}$ & $\begin{array}{c}-0.009 * * \\
(0.002)\end{array}$ \\
\hline Industry Fixed Effects & Yes & Yes & Yes & Yes & Yes & Yes \\
\hline $\mathrm{R}^{2 \mathrm{a}}$ & 0.5124 & & 0.5264 & & 0.5269 & \\
\hline Wald $\mathrm{Chi}^{2}(27)^{\mathrm{b}}$ & 139562 & 55429 & 137280 & 57298 & 150411 & 59785 \\
\hline Weighted Population Size & $11,753,385$ & $11,753,385$ & $11,753,385$ & $11,753,385$ & $11,753,385$ & $11,753,385$ \\
\hline
\end{tabular}

${ }^{*} p<.05, * * p<.01$. Standard Errors in parentheses. Occupation Fixed Effects = binary variables for six occupation types. Industry Fixed Effects $=$ binary variables for 14 industry categories. ${ }^{a}$ Probit does not generate meaningful $\mathrm{R}^{2}$ values. ${ }^{\mathrm{b}}$ The combination of survey and bootstrapping methods cannot be used to generate a meaningful overall $\mathrm{F}$ test or maximum likelihood for the probit analysis. Instead, we generate Wald chi ${ }^{2}$, which tests how far the set of estimated parameters are from zero. 
Table $3 b$ - Intersectional barriers and their interactions with the international orientation of the firm

\begin{tabular}{|c|c|c|c|c|c|c|}
\hline Dependent Variable: & Pay & $\begin{array}{c}\text { Supervisory } \\
\text { Position }\end{array}$ & Pay & $\begin{array}{c}\text { Supervisory } \\
\text { Position }\end{array}$ & Pay & $\begin{array}{c}\text { Supervisory } \\
\text { Position }\end{array}$ \\
\hline & Model 1 & Model 2 & Model 3 & Model 4 & Model 5 & Model 6 \\
\hline \multicolumn{7}{|l|}{ Predictor variables: } \\
\hline First Generation Immigrant & $\begin{array}{c}-0.032 * * \\
(0.003)\end{array}$ & $\begin{array}{c}-0.109 * * \\
(0.010)\end{array}$ & $\begin{array}{c}0.023 * * \\
(0.004)\end{array}$ & $\begin{array}{l}0.146^{* *} \\
(0.010)\end{array}$ & $\begin{array}{c}0.034 * * \\
(0.004)\end{array}$ & $\begin{array}{l}0.128^{* *} \\
(0.011)\end{array}$ \\
\hline Descendant of Immigrants & $\begin{array}{c}0.026^{* *} \\
(0.002)\end{array}$ & $\begin{array}{c}0.119^{* *} \\
(0.008)\end{array}$ & $\begin{array}{c}0.029 * * \\
(0.002)\end{array}$ & $\begin{array}{l}0.121 * * \\
(0.006)\end{array}$ & $\begin{array}{c}0.034^{* *} \\
(0.002)\end{array}$ & $\begin{array}{l}0.133^{* *} \\
(0.008)\end{array}$ \\
\hline People of Color & & & $\begin{array}{c}-0.078 * * \\
(0.004)\end{array}$ & $\begin{array}{r}-0.023^{*} \\
(0.010)\end{array}$ & $\begin{array}{c}-0.087 * * \\
(0.003)\end{array}$ & $\begin{array}{l}-0.025^{*} \\
(0.012)\end{array}$ \\
\hline Different Language & & & $\begin{array}{c}-0.074 * * \\
(0.003)\end{array}$ & $\begin{array}{c}-0.085^{* *} \\
(0.015)\end{array}$ & $\begin{array}{c}-0.077 * * \\
(0.003)\end{array}$ & $\begin{array}{c}-0.088^{* *} \\
(0.015)\end{array}$ \\
\hline Female $=1$, Male $=0$ & & & $\begin{array}{c}-0.125 * * \\
(0.003)\end{array}$ & $\begin{array}{c}-0.100 * * \\
(0.007)\end{array}$ & $\begin{array}{c}-0.118 * * \\
(0.003)\end{array}$ & $\begin{array}{c}-0.091^{* *} \\
(0.008)\end{array}$ \\
\hline \multicolumn{7}{|l|}{ Interactions: } \\
\hline $1^{\text {st }}$ Gen Immigrant* International & & & & & $\begin{array}{l}0.001 * * \\
(0.0001)\end{array}$ & $\begin{array}{l}0.002 * * \\
(0.0001)\end{array}$ \\
\hline Descendant* International & & & & & $\begin{array}{l}0.001 * * \\
(0.0001)\end{array}$ & $\begin{array}{l}0.002 * * \\
(0.0003)\end{array}$ \\
\hline People of Color*International & & & & & $\begin{array}{l}0.001 * * \\
(0.0002)\end{array}$ & $\begin{array}{c}0.00002 \\
(0.0006)\end{array}$ \\
\hline Language*International & & & & & $\begin{array}{l}0.0003^{*} \\
(0.0001)\end{array}$ & $\begin{array}{c}0.0001 \\
(0.0006)\end{array}$ \\
\hline Female* International & & & & & $\begin{array}{c}-0.001 * * \\
(0.0001)\end{array}$ & $\begin{array}{l}-0.002 * * \\
(0.0004)\end{array}$ \\
\hline $\mathrm{R}^{2 \mathrm{a}}$ & 0.5124 & & 0.5264 & & 0.5269 & \\
\hline Wald $\mathrm{Chi}^{2}(27)^{\mathrm{b}}$ & 139562 & 55429 & 137280 & 57298 & 150411 & 59785 \\
\hline Weighted Population Size & $11,753,385$ & $11,753,385$ & $11,753,385$ & $11,753,385$ & $11,753,385$ & $11,753,385$ \\
\hline
\end{tabular}

${ }^{*} p<.05,{ }^{* *} p<.01$. Standard Errors in parentheses. ${ }^{a}$ Probit does not generate meaningful $\mathrm{R}^{2}$ values. ${ }^{\mathrm{b}}$ The combination of survey and bootstrapping methods cannot be used to generate a meaningful overall $\mathrm{F}$ test or maximum likelihood for the probit analysis. Instead, we generate Wald chi ${ }^{2}$, which tests how far the set of estimated parameters are from zero. 
Table 4: Linear trend across intersectional groups that vary in the sum of barriers and advantages

\begin{tabular}{|c|c|c|}
\hline Dependent Variable: & Pay & Supervisory $\mathbf{P}$ \\
\hline & Model 1 & Model 2 \\
\hline \multicolumn{3}{|c|}{ Intersectional Groups } \\
\hline \multicolumn{3}{|c|}{ Omitted Group: Sum of 4 barriers present } \\
\hline Sum of 3 barriers present & $\begin{array}{c}0.082 * * \\
(0.007)\end{array}$ & $\begin{array}{l}0.005 * \\
(0.002)\end{array}$ \\
\hline Sum of 2 barriers present & $\begin{array}{c}0.127 * * \\
(0.007)\end{array}$ & $\begin{array}{c}0.061 * \\
(0.029)\end{array}$ \\
\hline Sum of 1 barrier present & $\begin{array}{c}0.146 * * \\
(0.006)\end{array}$ & $\begin{array}{c}0.063^{* *} \\
(0.019)\end{array}$ \\
\hline No barriers present & $\begin{array}{c}0.193 * * \\
(0.006)\end{array}$ & $\begin{array}{c}0.131 * * \\
(0.029)\end{array}$ \\
\hline 1 advantage present & $\begin{array}{c}0.258 * * \\
(0.007)\end{array}$ & $\begin{array}{c}0.146 * * \\
(0.030)\end{array}$ \\
\hline
\end{tabular}

Individual control variables in all specifications:

Firm control variables in all specifications:
Education Index, Years of Experience, Age, Unionization, Occupation Fixed Effects
Firm Size, International orientation, Foreign Competition Index, Relative Performance Index, Industry Fixed Effects

\begin{tabular}{lcc}
\hline Test for Linearity of Intersectional Groups & \\
Contrast of Marginal Linear Predictions Chi ${ }^{2}$ & 1706.52 & 22.34 \\
$\mathrm{P}>\mathrm{Chi}^{2}$ & 0.000 & 0.000 \\
\hline $\mathrm{R}^{2 \mathrm{a}}$ & 0.5203 & \\
$\mathrm{Wald} \mathrm{Chi}^{2}(35)^{\mathrm{b}}$ & 135525 & 59785 \\
Weighted Population Size & $11,753,385$ & $11,753,385$
\end{tabular}

${ }^{*} p<.05, * * p<.01$. Standard Errors in parentheses. Occupation Fixed Effects = binary variables for six occupation types. Industry Fixed Effects = binary variables for 14 industry categories. ${ }^{a}$ Probit does not generate meaningful $\mathrm{R}^{2}$ values. ${ }^{\mathrm{b}}$ The combination of survey and bootstrapping methods cannot be used to generate a meaningful overall $\mathrm{F}$ test or maximum likelihood for the probit analysis. Instead, we generate Wald chi ${ }^{2}$, which tests how far the set of estimated parameters are from zero. 